\title{
El ingenio de la diplomacia: Saavedra Fajardo, el conde de Rebolledo y los reyes del norte ${ }^{1}$
}

\author{
Adrián J. Sáez \\ Université de Neuchâtel \\ adrian.saez@unine.ch
}

Recepción: 29/04/2014, Aceptación: 01/07/2014, Publicación: 17/12/2014

\section{Resumen}

Uno de los caminos más interesantes — y menos transitados - para acercarse a las relaciones entre literatura y política se encuentra en la producción escrita de los diplomáticos. En esta ocasión, se propone un acercamiento a los casos de Saavedra Fajardo y el conde de Rebolledo, que de entrada guardan diversas similitudes de biografía y carrera. Además, una lectura frente a frente de la Corona gótica (1646) y la primera de las Selvas dánicas (1655) permite acercarse al carácter pragmático de la escritura de ambos ingenios, marcada por el giro hacia el norte de la política hispánica y porque significativamente echan mano del elemento neogótico para dos textos que deben leerse en diálogo con el contexto coetáneo.

Palabras clave

Diplomacia; ingenio; Saavedra Fajardo; Bernardino de Rebolledo; Corona gótica; Selvas dánicas; propaganda; mito neogótico

\section{Abstract \\ The Wit of Diplomacy: Saavedra Fajardo, the Count of Rebolledo, and the Kings of the North One of the most interesting — and less studied — ways to examine to the relationship}

1. Este trabajo se ha desarrollado durante una estancia de docencia e investigación en la Universidad de Córdoba en enero-febrero de 2014, en el marco del proyecto PHEBO: «Poesía Hispánica en el Bajo Barroco (repertorio, edición, historia)», FFI2011-24102 del Ministerio de Ciencia e Innovación y cuyo IP es Pedro Ruiz Pérez, a quien debo tanto la generosa invitación como muchas conversaciones provechosas. 
between literature and diplomacy is in the diplomats' writings. On this occasion, and approach to the cases of Saavedra Fajardo and the Count of Rebolledo, who since the beginning has some biographical and professional similarities in common, serves as preface to the comparison between the Gothic Crown (1646) and the first part of the Danish Selvas (1655): this perspective that allows to understand the pragmatic character of the works of both poets, which is marked by the turn to the north of the spanish politics and which meaningfully uses the neogothic element for these two texts, that has to be read in dialogue whith the coetaneus context.

\section{Keywords}

Diplomacy; wit; Saavedra Fajardo; Bernardino de Rebolledo; Gothic Crown; Danish Selvas; propaganda; neogothic myth

Uno de los valores fundamentales de La diplomatie de l'esprit (La diplomacia del ingenio) de Fumaroli es que pone sobre la mesa el valor de la diplomacia junto al arte del ingenio, en un atento repaso al giro político de la función que la literatura da en Francia entre la razón de estado y un nuevo concepto de sociedad ${ }^{2}$. Precisamente, los embajadores y otros agentes diplomáticos eran piezas fundamentales en el tablero de la política europea de los siglos XVI y XvII, ya que participaban en la primera línea de las tensiones entre la guerra y la $\mathrm{paz}^{3}$. Sin embargo, apenas se contempla todavía la producción escrita —y menos todavía la representación literaria- de estos hombres de poder, que defendieron los intereses de sus reinos con la pluma en «batallas de papel» junto a otros ingenios más alejados del mapa geopolítico del momento .

Es por ello que hay que ceder paso al ingenio de la diplomacia, si se me permite darle una vuelta de tuerca al marbete de Fumaroli, pues con este giro se abre una senda tan poco transitada como rica para entender el maridaje entre

2. Fumaroli (2011), con las reflexiones siguientes de Bély (2000) y Fumaroli (2013).

3. Sobre el afianzamiento y las caras de la diplomacia moderna, ver Lefevre (1923), Mattingly (1970), Anderson (1993), Ochoa Brun (1990-2006), Galende Díaz (1994), López Cordón (1996), Bély y Richefort (1998), Rivero Rodríguez (2000), Colomer (2003), Levin (2005), Ochoa Brun (2005), Bouzy (2006 y 2007), Martinengo (2006), Cardim (2008), Weller (2009), Siracusa (2010: 1-10), Duccini (2012), Lundell (2012) y Michon y Petris (2013).

4. Ver Arredondo (2011). 
literatura y política en el Siglo de Oro con la diplomacia como brújula y piedra de toque de estas relaciones. Desde un somero ejercicio comparativo entre los avatares de Saavedra Fajardo y el conde de Rebolledo paso posteriormente a comentar algunas ideas sobre sendos proyectos (la Corona gótica y la primera parte de las Selvas dánicas) que mantienen ciertos hilos comunes de concepción, función y sentido, que resultan tan reveladores en sus similitudes como en sus diferencias 5 .

\section{Los contornos de Saavedra Fajardo y Rebolledo ${ }^{6}$}

Escasa distancia temporal separa a Saavedra Fajardo (1580-1648) y a Bernardino de Rebolledo (1597-1676). Cercanía cronológica y marco histórico común constituyen el telón de fondo sobre el que se desarrolla un haz de relaciones entre dos hermanos de diplomacia que, con todo, no esconden diferencias de talante, funciones y empeños. Es decir: encuentros y desencuentros que delinean dos caras de la moneda del diplomático escritor (más que escritor diplomático) ${ }^{7}$.

Ambos vienen al mundo en la periferia de la corona hispánica, en Murcia (hacienda familiar el Raiguero) y León, respectivamente, desde donde se esfuerzan por acercarse al centro del poder y así pronto principian su carrera diplomática: algo antes Saavedra, que directamente se lanza a la escena política cuando pasa a Roma en compañía del cardenal don Gaspar de Borja, embajador de Espańa ante el papa, mientras Rebolledo primero toma el camino de la milicia, que más adelante compaginará con funciones diplomáticas. En efecto, si Rebolledo tomaba «ora la espada, ora la pluma», Saavedra Fajardo ejerce toda su vida activa como enviado español para negociaciones del más alto nivel, al punto de que en sus escritos resurgen aquí y allá los más diversos problemas que acosaban a ministros y diplomáticos, amén de cuestiones de máxima actualidad que conocía a la perfección. García López resume la cuestión:

5. A pesar de que los acercamientos a la producción escrita de diplomáticos y embajadores es bastante reducida, me preceden algunos acercamientos parejos: Fernández Daza-Álvarez (1995) se centra en Juan Antonio Vera y Zúñiga, conde de la Roca y autor del importante tratado El embajador (1620); el enfoque teórico de Hamtpon (2009) y Boadas Cabarrocas (2012b), que compara las gestiones de Saavedra Fajardo y Josep Fontanella durante las conversaciones de Westfalia. Con otros intereses puede verse Sáez (2012a y 2012b).

6. Este epígrafe rinde homenaje al trabajo de García López (1998). Para la vida de Saavedra ver Boadas Cabarrocas (2012a: 31-77) y luego González Palencia (1946) y Fraga Iribarne (2008); una acertada y rápida síntesis biográfica en García López (2006: 9-15; y 2010). Sobre la biografía de Rebolledo, ver del Río Alonso (1927) y Casado Lobato (1975); y los perfiles bosquejados en González Cañal (1997: 7-12; y 2010).

7. Los paralelismos entre ambos ingenios apenas han sido apuntados a vuelapluma a propósito de la Selva militar y politica (ver infra). En otro lugar, González Cañal (2003) saca a relucir las enseñanzas emblemáticas de Saavedra Fajardo a propósito de la Vida de Boecio (Frankfurt, Gaspar Rotelio, s. a. [h. 1642]) de Francisco de Moncada, publicado a instancia directa de Rebolledo. 
Don Diego será —y lo será a lo largo de su vida, y por encima de todo— un diplomático. Un profesional de la diplomacia, cosa que Quevedo nunca fue. Sus primeras obras surgen con naturalidad de su actividad diplomática, repiten el camino de su correspondencia antes de dar en página impresa, y tienen idéntico lector privilegiado: el conde-duque de Olivares. Sin embargo, no parece que pueda aplicarse a don Diego el guión que alguna vez se ha utilizado para los embajadores de la Señoría de Venecia. Piezas de su correspondencia podrían entenderse en esa forma, pero su obra no se limita a mera «relación de embajada». [...] Pero si puede establecerse discontinuidad entre la correspondencia y la obra teórica, no así en el hombre. Entre el tratadista y el diplomático no hay soluciones de continuidad, sino una relación intensa, y tanto más estrecha como que — curiosamente- la documentación conservada nos lleva a pensar que su correspondencia corre paralela a sus obras teóricas ${ }^{8}$.

En cambio, Rebolledo tarda en tener su primera misión diplomática hasta 1636, cuando, tras más de veinte ańos (desde 1611) de combatir en diversas empresas italianas, se le encarga participar en las negociaciones entre el emperador, el rey de Hungría y los electores de Maguncia y Alemania, y aun entonces no pasará de ser un trámite — que le reporta su nombramiento nobiliario—continuado en 1644 con la misión de conferenciar con plenipotenciarios alemanes. De ahí saltará a la escena diplomática únicamente en 1647, momento en que es comisionado como enviado plenipotenciario a Dinamarca, una suerte de exilio del que no pocas veces pedirá escapar.

Se advierten dos diferencias sustanciales en este ejercicio diplomático: una de estatuto y otra funcional. Acaso lo más importante sea que Rebolledo parte al norte con todas las credenciales para su embajada, mientras Saavedra Fajardo no alcanzó nunca el grado de embajador stricto sensu: lastrado por su estatuto social, participaba de un concepto más técnico que aristocrático de la diplomacia, por lo que siempre se orientaba a funciones negociadoras ${ }^{9}$. Diferencia sustancial en lo que tiene de autoridad y prestigio pero que no lograba alejar las dificultades y penurias que perseguían a los diplomáticos allá donde fueran: si no parece que a Rebolledo le faltaran las cartas con instrucciones y poderes que minaron gravemente las labores de Saavedra Fajardo ante los XIII Cantones de esguízaros para alegría de los franceses-, tanto uno como otro sufrieron la falta de caudales suficientes para mantener una imagen adecuada, correr con otros muchos gastos menudos y hasta para desplazarse ${ }^{10}$. Asimismo, el olvido en que parece condenado por la corte, su quebrantada salud y sobre todo la falta de permiso y fondos

8. García López (1998: 249). Fraga Iribarne (2008: 30-31) anota que, aunque «no trató de un modo sistemático los problemas de la diplomacia, [...] el tema resurge constantemente en sus escritos». 9. Cardim (2008: 125). A diferencia de Saavedra, Rebolledo descendía del señor de Irián.

10. Ver más sobre este mal crónico en Corredera Nilsson (2009: 242). Para la etapa suiza de Saavedra, ver Sánchez Jiménez y Sáez (2014). 
para regresar a la patria causan en Rebolledo un penoso sentimiento de destierro, del que da cuenta en varios poemas (núms. 202, 206, 210, 211, 214 y 228 de Ocios), buenos documentos para asomarse a la vida diplomática de entonces. Por fortuna, tenía buenas relaciones con los monarcas daneses, al punto que la reina Sofía Amalia de Lunenburg le cede su palacio de Hersholme por un año, donde dará forma a sus poemas mayores - Selvas dánicas incluidas-, un privilegio del que no disfrutará Saavedra en los tiempos de espera. La periferia de Rebolledo es también central en tanto está bien relacionado con la corte danesa ${ }^{11}$.

Variación tanto más esencial cuanto que las funciones tampoco son idénticas: a más de las conversaciones con plenipotenciarios alemanes a la caza de fuerzas contra Francia, la embajada de Rebolledo en la corte de Dinamarca se antoja cómoda, toda vez que esta sede solamente se ve acosada en 1658-1659 durante la guerra sueco-danesa; por el contrario, Saavedra Fajardo se mueve a salto de mata entre los escenarios geopolíticos más complejos de una Europa devastada por la guerra de los treinta años, con el complejo problema helvético y las conversaciones de Westfalia a la cabeza. Tal vez pueda aducirse que Rebolledo ya había degustado su dosis de guerra en el mismo frente de batalla durante su etapa militar, pero la impresión que deja esta compulsa es clara: Saavedra Fajardo parece ser el agente especialmente reservado para acudir a las situaciones más comprometidas del tenso panorama europeo.

Tampoco la fortuna les depara los mismos favores, pues se muestra mucho más generosa con Rebolledo. Ya la concesión de un premio que comparten muestra esta dinámica: si los dos disfrutan del hábito de Santiago, es Rebolledo quien a pesar de su menor edad es nombrado caballero primero en 1628, con lo que gana por la mano a Saavedra, que ha de esperar hasta $1640^{12}$. Después, por mucho que se pueda hacer el esfuerzo de entender en su contexto los beneficios que pueden tocar en suerte a un religioso y un soldado, la canonjía de Santiago de Compostela no puede compararse con el meteórico ascenso de Rebolledo hasta ser capitán general de artillería del ejército. Ciertamente, haciendo caso omiso de los puestos diplomáticos que no viene al caso deslindar, Rebolledo recibe muchos más cargos y honores, entre los que se pueden destacar el título condal que se le concede desde el Sacro Imperio (1636, aceptado al recibir el permiso de Felipe IV en 1638) y la Orden de Amaranta concedida por Cristina de Suecia.

Eso sí, las etapas y los escenarios que recorren siguen caminos paralelos a caballo entre Italia y el centro y norte de Europa: si Saavedra da sus primeros pasos ante todo en Roma (1617-1633), desde donde pasa a una segunda fase centroeuropea (1633-1645), primeramente afincado en Baviera y con la misión de negociar con los esguízaros y luego ya como enviado plenipotenciario a las conversaciones de Münster hasta 1645 (hasta ser relevado por el conde de Pe-

11. Ver Martín Puya (2013).

12. Más detalles sobre este beneficio de Saavedra en Boadas Cabarrocas (2012a). 
ñaranda), durante su etapa italiana Rebolledo se dedica en exclusiva a la carrera militar, que no comienza a virar hacia la diplomacia hasta su destino en Flandes y Alemania, para centrarse definitivamente en sus funciones de embajador en $1647-1648^{13}$.

Justamente los múltiples viajes y las estancias en el extranjero abarcan buena parte de las vidas de ambos ingenios. De hecho, de ahí deriva la «sorprendente modernidad» de los textos de Saavedra Fajardo, en contacto con las novedades más importantes de la época y compuestos en su mayor parte desde la periferia del imperio ${ }^{14}$. Caso más que parejo es el de Rebolledo, que gracias a sus viajes por el norte de Europa pudo contactar con escritores y lecturas de muy diverso signo (Descartes, Gassendi, etc.), gracias a los que tuvo pronta noticia de ideas filosóficas y avances científicos mucho antes de que llegaran a España, razón por la que se tiene a Rebolledo por un testigo privilegiado del cambio de paradigma de finales del siglo XviI ${ }^{15}$. Cada uno en su medida, Saavedra y Rebolledo se adaptaron y participaron de los cambios y las innovaciones que les había tocado vivir.

Tanto uno como otro son ingenios de obra tardía: las primeras calas de Saavedra son las Introducciones a la politica y la Razón de estado del rey católico don Fernando (1630-1631, manuscritos), cuando es ya «un fogueado diplomático en trance de coronar una brillante carrera política ${ }^{16}$, al tiempo que Rebolledo no se cuida de componer e imprimir sus textos hasta su embajada en Dinamarca. Desde ahí, escogen opciones diferentes: en efecto, el lugar en las letras hispanas de Rebolledo se debe a su poesía, mientras Saavedra debe su fama a sus tratados y opúsculos políticos ${ }^{17}$.

Y es que a más de similitudes en peripecias vitales, escritura pragmática y hasta esprit, Saavedra y Rebolledo se hermanan precisamente en sus creaciones, pues de ellas se desprenden de entrada tres importantes rasgos compartidos: la compaginación de la diplomacia con la escritura, que se define por un carácter pragmático y fuertemente relacionado con el tornadizo universo de la política, junto a la condición periférica (por redacción y edición) de sus textos. Saavedra saca a la luz las dos ediciones (Mónaco de Alemania, Nicolao Enrico, 1640; Milán, [s. i.], 1642) de sus Empresas politicas—con variaciones sustanciales al

13. Su carta credencial fue firmada en octubre de 1647 en El Escorial, llegando a la corte danesa en marzo de 1648, pero la muerte del rey Christian IV hizo que su entrada oficial ante Frederick III tuviera que retrasarse hasta julio de 1648, ya con nuevos documentos (Corredera Nilsson, 2009: 218).

14. García López (1998: 238).

15. González Cañal (2008: 78-79) y Prot (2013). Además, González Cañal (2004: 607; 2008b: 169 y 172) señala que su alejamiento de España y de las polémicas literarias nacionales dificulta la adscripción de Rebolledo a ninguna escuela poética.

16. García López (1998: 238).

17. Los versos (castellanos y latinos) de Saavedra apenas han despertado atención crítica hasta hace poco. García López (2008: 73) ha editado estas poesías y señalando, en base a comentarios de la época, que deben de haberse perdido muchas otras. 
hilo de la polémica maquiavelista - fuera de la península ${ }^{18}$ y muchos de sus panfletos se destinan a refutar ataques foráneos.

Todavía más clara es la estrategia de Rebolledo, que no solamente publica toda su producción en el extranjero sino que demuestra preocuparse por la salida impresa de sus textos, que suele sacar en el mismo taller (la prestigiosa Officina Plantiniana de Amberes se encarga de los Ocios, 1650; y del Idilio sacro, 1660) y luego recopila en unas completas Obras poéticas (1660-1661, 3 vols). Este estado de cosas revela que la dedicación diplomática va unida al cuidado editorial — y aun a la actividad creadora-, porque la publicación de su obra es anterior a su regreso a España, en un signo del interés de Rebolledo por granjearse prestigio y apoyos de cara a salir del impasse en el que se encontraba estancado, como igualmente demuestran las dedicatorias de sus escritos, que se destinan siempre a poderosos daneses, imperiales y españoles ${ }^{19}$. En otras palabras: los intereses literarios se entrecruzan con gestiones diplomáticas (contactos y negociaciones con enviados de otras delegaciones) y motivaciones personales (el anhelado retorno a casa).

\section{Los guińos de un tratado y un poema}

Buenos ejemplos de todo lo que vengo comentando son la Corona gótica (Münster, Juan Jansonio, 1646) de Saavedra Fajardo y las Selvas dánicas (Copenhagen, Pedro Morsingio, 1655) de Rebolledo, ambas fraguadas en un contexto común de reordenación geopolítica, a medias entre el otium y el negotium de sus misiones y con una similar intención didáctico-política, manifiesta a través de las armas que mejor dominaba cada ingenio (prosa frente a verso).

La redacción de la Corona gótica, castellana y austríaca, políticamente ilustradase se sitúa en 1643-1645 como producto del ocio activo — tan caro a Saavedra-con el que compensaba las largas esperas de las conversaciones por la paz de Münster, según confiesa en las palabras preliminares (77). Se trata de una muestra más, del canto de cisne en su campaña propagandística a favor de los intereses de la monarquía hispánica en Europa, que frente a los opúsculos y tratadillos lanzados anteriormente a esta "contienda de papel» (Carta de un holandés a otro, Suspiros de Francia, etc.), en esta ocasión se adentra significativamente en el género historiográfico. Saavedra aclara en la dedicatoria que su propósito es reducir

18. Ver la fina explicación de García López (2012).

19. A la reina danesa dirige las Selvas dánicas (1655); La constancia victoriosa. Égloga sacra (1655) a Cristina de Suecia; el Discurso apologético a Joachim Gestorf, senador y gran maestre de Dinamarca; la Selva militar y politica (1652) a Fernando IV, rey de romanos; el discurso sobre Epicuro (1661) al barón Juan de Goes, embajador del emperador en la corte dánica; y ya más adelante apunta a la corte española con la Selva sagrada (1656), que es para Felipe IV (1656), el Idilio sacro (1660) para la reina Mariana de Austria y la reedición de la Selva militar y política (1661) es para el príncipe Felipe Próspero. 
«en un breve volumen las historias de los reyes godos de España, [...] de tal suerte dispuestas, que no solamente hallase Su Alteza [el príncipe Baltasar Carlos] entero conocimiento dellas, sino también advertidas en los casos las máximas políticas» (73), porque «antes mejor della [la historia gótica] que de la griega o romana se puede aprender la verdadera razón de estado» $(74)^{20}$. El texto se estructura en un recorrido por la historia de treinta y cinco reyes godos (de Alarico a don Rodrigo) a lo largo de treinta capítulos, en los que se ofrece una serie de enseñanzas de gobierno a partir de "experiencias y acciones», de modo que la Corona gótica vale como la versión práctica de la teoría política de las Empresas políticas, las dos caras de la misma moneda, destinada a perfilar el retrato del príncipe perfecto ${ }^{21}$.

El carácter didáctico, consustancial a los tratados de educación de príncipes, se orienta aquí a un fin inmediato derivado del contexto bélico: replicar a «algunos libros de pretensos derechos sobre casi todas las provincias de Europa» que, publicados durante el congreso de Münster, dificultaban «y aun imposibilitaba[n] la conclusión de la paz» con sus pretensiones, de modo que era conveniente dar respuesta mediante «una historia [que] mostrase claramente los derechos legítimos en que se fundó el reino y monarquía de España, y los que tiene a diversas provincias» (77). Esta declaración de intenciones advierte ya del carácter polémico de la Corona gótica, al tiempo que revela la labor de reescritura interesada de la historia que realiza Saavedra. Leídas a esta luz, las continuas referencias a los rivales de la Gallia gothica apuntaría al enemigo francés del presente ${ }^{22}$.

Desde esta ladera, se dice que la Corona gótica escondía entre sus páginas un secreto designio político, a saber: el intento de acercamiento a los suecos de cara a lograr una alianza espańola con la corona de Suecia mediante el matrimonio de la reina Cristina con Felipe IV, un pacto que hubiese cambiado, de llegar a efecto, el rumbo de la guerra de los treinta ańos ${ }^{23}$. La idea se repite como un eco sin fin (González Palencia, 1946: 119b; Dowling, 1957: 77, etc.), pero se apoya solo en unos pocos indicios, los más de ellos externos al texto: así, la amistad con su amigo Schering Rosenhane, el representante sueco, con quien al parecer

20. Proyecta también dar cuenta de los «de Asturias, de León y de Castilla», pero esta tarea la llevará a cabo Alonso Núnez de Castro algo más adelante.

21. Así se lee en "Al príncipe nuestro señor»: «En la Idea de un príncipe político-cristiano presenté a vuestra alteza la teórica de la razón de estado, y agora ofrezco la práctica advertida en la Vida de los señores reyes godos de España, y de los que sucedieron a ellos en Asturias, en León y en Castilla» (12). Rosa de Gea (sin fecha: 12-13) recupera esta dedicatoria, en un trabajo que vale a la perfección como pórtico a la Corona gótica. Villacañas (2008: 13) indica que esta tarea es «inseparable de su proyección internacional [de Espańa] como primera potencia europea».

22. Rosa de Gea (sin fecha: 11) mantiene que el texto lanza un mensaje directo al nuevo papa Inocencio X, para que no continúe el apoyo que su antecesor Urbano VIII prestaba a la causa francesa.

23. González Palencia (1946: 119b) y Murillo Ferrol (1989: 120). Sanmartín (2007: 210) va más allá al sugerir que la elaboración de la Corona gótica debía de contar «con la aquiescencia de dignatarios del gobierno». Sobre la relación de la reina sueca y Saavedra, ver González Cañal (1986). 
conversaba un acuerdo hispano-sueco ${ }^{24}$; y la cercanía y simpatía que el tema de su tratado podría despertar en los sueceses. En todo caso, esta estrategia - fuese o no verdad- solo adquiere sentido a la luz del contexto de guerra y paz, como una nueva arma de papel destinada a legitimar las aspiraciones de la monarquía hispánica en un momento en que estaba en juego el nuevo panorama geopolítico. Este era el fin confeso del libro y no la posible maniobra diplomática, aunque es normal que esta jugada — de existir — se guardase en la manga.

Con todo, no es menos cierto que el secreto no está reñido con la sutileza, por lo que bien podría esperarse alguna suerte de guiño a los potenciales aliados, mas nada se dice a las claras ni en las dedicatorias (a don Gerónimo Serra Marín y al príncipe) ni en el cuerpo del texto. Desde fuera se puede dar por bueno que la historia gótica remite al común origen de ambas coronas, y acaso Saavedra pretendía que las antiguas disputas sobre la ascendencia goda entre los Habsburgo y la monarquía sueca ${ }^{25}$ se olvidaran y sirviesen de fundamento para un acercamiento hispano-sueco. Nada parecido hay a la algo confusa Monarquía eclesiástica o historia universal del mundo (Salamanca, Juan Fernández, 1588) de fray Juan de Pineda, que no solamente relata el origen y las peripecias de la «nación goda» desde el norte hasta España (parte II, libro 13, caps. 25-29; libro 16, caps. 5-29; III, libro 18, caps. 2-3) sino que más adelante también refiere la fortuna de los godos que permanecen en Dania y Suecia (IV, libro 30, caps. 1-25) ${ }^{26}$. El único signo claro viene ya casi al final, tras el epitafio del rey don Rodrigo:

Lo que en él se refiere, que don Rodrigo fue el último de los reyes godos, no se debe entender en la sangre, sino en el título, porque don Rodrigo y sus predecesores se llamaron reyes godos, y sus sucesores reyes de Asturias, de León y de Castilla; habiendo caído con don Rodrigo el imperio gótico, porque de allí adelante quedando casi extinguida la nación goda, solamente la española mantenía dentro de los montes la libertad, y allí levantó otro nuevo ceptro en la misma sangre real de los godos, eligiendo por rey a don Pelayo, con diverso título, armas y insinias reales, continuándose en sus descendientes hasta estos tiempos la nobilísima familia de los Balthos, tan antigua en los reinos de Scandia, que della y de sus ceptros se ignora el origen $(30,571-572)$.

En estas palabras Saavedra Fajardo se esfuerza por reforzar la continuidad de la monarquía visigoda, que pervive en los «reyes de Asturias, de León y de Castilla» — tras quienes se adivina a los posteriores Habsburgo—, aunque con otro tí-

24. Bouzy (1999), Fraga Iribarne (2008: 545-551) y Corredera Nilsson (2009: 118, 120, 124125, 130-131, 169). Clavería (1954: 108) consideraba que en realidad el texto «no puede ser juzgado como mero oportunismo para congraciarse con los diplomáticos suecos». Un panorama de los contactos hispano-suecos en Mörner (1999) y Corredera Nilsson (2009: 116-172).

25. González Blanco (2000: 146-149; y 1991: 26).

26. Söhrman (1998: 950-951) y Corredera Nilsson (2009: 163); ver Chaparro (2003). 1588 es la fecha de la primera edición de las cinco partes de la historia de Pineda. 
tulo, al tiempo que tiende un lazo de hermandad con «los reinos de Scandia», tras quienes en el contexto de las negociaciones de Westfalia se puede ver a los sueceses. No en vano, Covarrubias ya precisaba el origen septentrional de los godos, que salieron de «una gran provincia que llaman Scandia y Escandinavia», donde los reinos principales eran "Gotia, Noruega, Suecia y Dania»" Así pues, no parece baladí que esta fugaz nota final pueda servir de pista de lectura del tratado en su conjunto, ya que otorga una nueva dimensión actual al texto que se suma a la defensa de las legitimidades territoriales de la monarquía hispánica.

La clave de este nivel de lectura se encuentra en el mito neogótico, sobre el que se asienta una cierta concepción de la identidad nacional compartida por España y Suecia. En efecto, desde temprano la imagen del godo se empleaba tanto en la historia como en la ficción como instrumento de construcción de la identidad española, en tanto el reino visigodo constituía —al menos así se veía- la piedra de toque que permitía enlazar el antes y el después de la dominación musulmana, trazar una cierta continuidad con el imperio romano y establecer la naturaleza cristiana de la monarquía hispánica. Asimismo, el uso - y abuso - de la figura del godo se imbricaba fuertemente en las disputas por la legitimidad del poder, tanto en el terreno interno (caso del programa de Felipe V) como externo (valga la Corona gótica). El pasado visigodo, por tanto, se mostraba en España «como un filón inagotable a efectos de esa reelaboración identitaria ${ }^{28}$. Esta herencia bien conocida también pervivía en Suecia, donde los reyes se decían señores de Gocia y Vandalia como descendientes directos de los godos, y donde renace el interés por la esencia gótica durante el siglo XVI, según reflejan —entre otros escritos - los hermanos Johannes y Olaus Magnus en sus respectivas Historia de omnibus gothorum sveonumque regibus (Roma, Olaus Magnus, 1554) e Historia gentibus septentrionalibus (Roma, Olaus Magnus, 1555), que defienden el origen nórdico de los godos, quienes luego se extendieron por diferentes territorios europeos ${ }^{29}$.

Más allá de las reflexiones sobre la materia nacional a las que se prestaba esta similar concepción del pasado, en la escena diplomática de la década de 1640 se aceptaba la existencia de un antiguo y lejano lazo de unión fundamentado en el origen norteño de los godos, acrecentado por el interés que la potente entrada de Suecia en la guerra de los treinta años despertaba en la opinión pública. Corredera Nilsson recuerda que no solo el rey Gustavo Adolfo de Suecia - ni tampoco la reina Cristina - tenía un gran eco en la historiografía y la propaganda del momento, sino que el común origen godo era un recurso que la diplomacia hispánica

27. Sobre el goticismo sueco y algunos contactos con el caso español, ver Ekman (1962), Johannesson (1991), Söhrman (1998, 2002, 2005a y 2005b), y Corredera Nilsson (2009: 157-172).

28. Fernández Albadalejo (2007: 293); ver también Clavería (1973) y Redondo (1992), entre muchos otros estudios sobre el asunto.

29. Corredera Nilsson (2009: 162-172); Carta de Peñaranda a Pedro Coloma de 9 de diciembre de 1945, recogida en Corredera Nilsson (2009: 273). 
y sueca empleaban para intentar ganarse el apoyo mutuo, al punto que el conde de Peñaranda recuerda que los sueceses le solían decir que «todos somos godos». Saavedra no podía ser ajeno a este abanico de ideas y rumores que responden al giro de la política española hacia el norte que se había traducido en una apuesta clara por acercarse a Suecia especialmente a partir de $1645^{30}$. Es justo entonces cuando Saavedra, apartado del engranaje oficial, deja de participar en las negociaciones de Westfalia y en su tiempo de ocio activo emprende - para dar carpetazo si no inicio- la redacción de la Corona gótica: muchas casualidades juntas para no tener un fondo de verdad. Tal vez la supuesta propuesta saavedriana de unir las coronas sueca y española mediante un matrimonio no pasase de ser «una pequeña chanza para lisonjear a los suecos», pero el fundamento era una idea que se estaba explotando al calor de las necesidades y los intereses del presente más inmediato, ese que Saavedra enlazaba con el pasado mediante el goticismo ${ }^{31}$.

Resulta muy ilustrativo carear este caso con las Selvas dánicas del conde de Rebolledo, que se mueve dentro de unas coordenadas algo diferentes. Este curioso poema didáctico se divide en dos secciones, que no han merecido la misma valoración: en la primera de ellas se ofrece una genealogía poética de los monarcas daneses (con el nombre de "L'aula», 7-80), mientras en la segunda («Hersholme», 81-175) se presenta una suerte de descripción de las tierras del norte que no solo interesa por adentrarse en tierras menos conocidas y teñidas de fantasía. Los conocimientos geográficos, el interés por cuestiones científicas de la más rabiosa actualidad (atomismo, heliocentrismo, etc.) que sale a relucir entre verso y verso de esta segunda selva han favorecido la consideración de Rebolledo como un precursor de las ideas ilustradas y del nuevo paradigma racional y, con ello, han centrado la lupa de la crítica. Sin embargo, la historia de los reyes daneses que le precede merece tenerse en cuenta para no falsear ni fragmentar el sentido del poema.

Para ello vienen bien comenzar por los preliminares, que se componen de tres poesías, un grabado y la dedicatoria. Rebolledo abre fuego con un poema en elogio del artífice del retrato de Sofía Amalia de Lunenburg, reina de Dinamarca y Noruega, con algunos de los topoi habituales en alabanza de la pintura. Este primer paratexto hace pareja con el retrato que antecede a la dedicatoria, que en conjunto se limitan a poner a la reina en una posición privilegiada desde el incipit, pues no en vano las Selvas dánicas nacieron durante la estancia en un palacio cedido por quien parece ser su protectora durante la embajada. Entre los primeros versos de Rebolledo y la imagen se interponen dos sonetos que Scipione Mariotti, secretario del duque Juan Federico (Johan Frederik) de Branswick y Lunenburg, dedica a cada una de las dos silvas. Junto con las buenas palabras de

30. Corredera Nilsson (2009: 128) detalla que «[e]s sintomático que las relaciones con los suecos se reiniciaran a partir de mediados de 1645, tras un año en "barbecho"»; ver también Corredera Nilsson (2011), trabajo que manejo gracias a la generosidad de su autor.

31. Corredera Nilsson (2009: 131 y 168-169). 
rigor, dan algunas indicaciones sobre el poema dánico: así, este cortesano explica que en la primera selva se rinde honor a la casa real danesa («suoi regi antichi hor glorioso il rende»), de la que a la postre se dice que tiene la gloria «d'haber sido la primera» (175).

Esta primera selva dánica se compone de doce silvas métricas numeradas, un conjunto que se puede dividir internamente en tres secciones de extensión variable: 1) el exordio introductorio (I), 2) la historia y genealogía de los reyes de Dinamarca (II-XII) y 3) una última conexión con el presente (final de XII). El comienzo del poema constituye en esencia un elogio del rey que gobernaba entonces, Federico III, «monarca digno de las tres coronas / de justicia, prudencia, fortaleza», porque introdujo «la luz de la católica doctrina» frente «a peligrosos dogmas» (7-8), y a la nuevamente celebrada Sofía. Solamente después se explica la etimología de Dania, nombre que procede de su fundador Dan, tras lo que sigue un recorrido genealógico por los sucesivos reyes daneses, para cerrar con los monarcas del presente y los buenos augurios que prometen, de modo que el ejercicio de captatio abraza la historia real danesa.

A diferencia de la mesura que mostraba Saavedra en sus intenciones, Rebolledo prefiere una estrategia de elogios directos y claros, movido por una motivación más inmediata como parece ser la búsqueda de apoyos en las más altas esferas según una doble intención personal y política: personal, porque el poeta parece aspirar a una protección de los reyes y otros poderosos daneses que mitigue las difíciles condiciones materiales de su embajada; y política porque, aunque no haya espacio para lecciones de gobierno, no cabe duda de que la captación de favores y aliados en la corte danesa forma parte de las labores de todo buen diplomático. Con todo y ello, el olvido en que se sentía condenado Rebolledo y sus dificultades económicas sumado a la reducida importancia de Dinamarca en el momento, que apenas se estaba recuperando de las duras condiciones que le habían quedado de su derrota frente a Suecia en $1645^{32}$, parecen mostrar que las miras del poeta tenían un claro guińo pro domo sua —si no acaso pro pane lucrando - antes que políticas.

Nada de ello resta valor a la apuesta estética de las Selvas dánicas, un poema genealógico que se construye a modo de una rápida visión que arranca de la Historia danesa (Gesta Danorum) de Saxo Gramático. Rebolledo realiza un ejercicio de síntesis de un libro conocido en su tiempo por la princeps de Christiern Pedersen (1514, con varias reediciones) y la edición al cuidado de Staphen Staphensen $(1644)^{33}$. Una mirada al hipotexto revela algunas claves de esta primera selva dánica: Rebolledo mantiene el carácter dramático de los acontecimientos, una sucesión constante de conflictos dinásticos y guerras vecinales (especialmente con Noruega y Suecia), al tiempo que concede una especial atención a

32. Corredera Nilsson (2009: 44-46, 120 y 217-218).

33. Para todos los detalles sobre la gesta dánica, ver Ibáñez Lluch (2004). 
la religión cristiana, desde que llega la noticia de la fe verdadera en tiempos del rey Gormo (V, 29-30). Además de eso, es posible que la estructura general de las Selvas dánicas, con una primera parte histórica y otra científica, también tenga una deuda con la bipartición de la Historia danesa, solo que significativamente Rebolledo reduce al mínimo el componente legendario para dar entrada a las nuevas ideas del momento.

En todo caso, el poeta sabía muy bien que la materia histórica escogida requería de una serie de adaptaciones a la hora de reescribirse en verso, empezando por la labor de selección de hechos y reyes comentados ${ }^{34}$.Los episodios presentados son, a la fuerza, escasos, pero entre los pocos que se comentan y la retahíla de nombres se hallan ciertos puntos significativos que de hecho guardan ciertas similitudes con la historia de los reyes godos pintada en la Corona gótica de Saavedra Fajardo, como la importancia de la religión y la exposición de modelos de virtudes o, al revés, la condena de vicios como la tiranía (Olao en IV, 26-27), el incesto (Erico IV, que tiene un "hijo de su hermana», VIII, 50), el fratricidio (Abel, en IX, 56), etc., así que comparten una visión providencialista de la historia y la presentación de figuras ejemplares (a contrario). Sin embargo, creo que el mayor interés del poema reside en la renovadora asociación de forma y contenido, porque trata de transmitir un contenido útil mediante el dulce cauce del verso, que facilita la difusión de este asunto didáctico y en principio más apto para su desarrollo en forma de ensayo o tratado. Así se ha juzgado también la Selva militar y política (1661), otro poema didáctico de Rebolledo elogiado en el siglo xvıII por sus enseñanzas militares y posteriormente criticado porque se entiende que la materia no es fácil de elevar con las alas de la poesía ${ }^{35}$. En ambos casos se trata de una decidida apuesta por la poesía didáctica, un modelo que reformula el par horaciano dulce et utile y que conoce su etapa de esplendor en el siglo XvIII, al que decididamente se encamina Rebolledo. Así lo expresa Ruiz Pérez:

Alejado de la pretendida objetividad de la tratadística, la poesía didáctica, a la zaga de las Georgicae, mantiene, con los componentes expresivos ligados a la peculiaridad de la prosodia, un componente de subjetividad que desde Montaigne se estaba incorporando al ámbito de la prosa, dando una vitalidad moderna al clásico formato de la oratio o discurso, en cualquiera de los genera fijados por Quintiliano. Algo de pluma

34. En cada una de las once silvas el número de reyes comentados varía (de tres a diez), y en varias ocasiones se aprovecha el cambio de silva para saltar algunos años y personajes.

35. Así se expresa todavía González Cañal (2008b: 175). Es el texto generalmente relacionado con Saavedra Fajardo: entre dardo va y dardo viene, Menéndez Pelayo (1953: 141 y 144) establece una comparación clave para este "supuesto poema»: «Hubiérale escrito en prosa y sería tan leído como las Empresas de Saavedra Fajardo»; sobre este parentesco vuelve Díaz-Plaja (1937: 209), quien indica que en esta exposición de «los frutos de su experiencia política», Rebolledo escribe una obra «en la línea de Saavedra Fajardo, escritor y diplomático como él»; mientras González Cañal (2008b: 179-180) ve estas ideas lógicamente emparentadas con las expuestas por Saavedra Fajardo y enmarcadas en el marco de los tratados de educación de príncipes. 
soluta se traslada con esta actitud y encuentra su mejor acomodo en el verso, del mismo modo que su particular fluir se presta al despliegue de una estructura no tan condicionada por la rigidez de las normas, bastante escolásticas, de la tratadística ${ }^{36}$.

Con sus dos poemas, Rebolledo prueba el verso como vía de enseñanza de la historia (la primera de las Selvas dánicas) y la política (Selva político militar). Una de las razones que explica esta elección es el intento de renovación de la más generalizada difusión en prosa de las ideas de gobierno, mientras de otro recupera el cauce del verso empleado en la Edad Media, con ejemplos tan señeros a sus espaldas como el Rimado de palacio (cc. 477 y ss.) del canciller Pérez de Ayala ${ }^{37}$ y el Doctrinal de privados del marqués de Santillana, que en los siglos XVI y XVII persistía en la emblemática; más cerca, estas lecciones en verso se relacionan claramente con los poemas político-morales, muchos de ellos en forma de epístola, en los que unos cortesanos regalaban una serie de consejos desde su atalaya de buenos y experimentados conocedores de la política cortesana ${ }^{38}$, una perspectiva que tiene más de un paralelo con la práctica de Rebolledo, que difunde sus conocimientos históricos y políticos en verso. Por último, la selección del molde poético tiene que ver con el prestigio que el cultivo de la poesía tenía entre los cortesanos desde Castiglione.

\section{Final: diplomacia e ingenio}

En suma, el diálogo entre las carreras de Saavedra Fajardo y Rebolledo descubre un manojo de rasgos comunes claramente derivados de su experiencia como diplomáticos al servicio de la monarquía hispánica, mientras una revisión de la Corona gótica junto a la primera de las Selvas dánicas permite adentrarse en dos interesantes tentativas por una cara más de la política hispánica como es la naturaleza pragmática de estos escritos diseńados por y para el universo de la política. Aunque con apuestas estéticas de diverso signo y diferencias significativas, ambos textos constituyen una suerte de historias de reyes que se valen del elemento neogótico —en distintas dosis — según estrategias y funciones diferentes, desde la intención polémica (una lanza por la legitimidad española con la mirada puesta en Suecia) hasta una captatio interesada (una petitio más personal a los reyes daneses), que siempre adquieren sentido cabal en el contexto, marcado a fuego por sus labores diplomáticas. Porque, al fin, diplomacia e ingenio van de la mano.

\section{Ruiz Pérez (2014).}

37. Ver Bizzarri (2011a, 2011b y 2012), que indica la existencia de un manuscrito (BNE: Mss/9429) que recoge solamente la sección de speculum principis, y traza los contactos del género con los sermones, las listas de vicios y virtudes, etc. Ańade: «La falta de un modelo preciso que caracterice al "espejo de príncipes", factible de ser escrito en prosa o en verso, en un estilo arabizante o escolástico, como discurso organizado o como simple lista de sentencias y ejemplos, facilitó no sólo su constante metamorfosis sino también su pervivencia» (2012: 164)

38. Dadson (2000). 


\section{Bibliografía}

Arredondo, María Soledad, Literatura y propaganda en tiempo de Quevedo: guerras y plumas contra Francia, Cataluña y Portugal, Madrid / Frankfurt, Iberoamericana / Vervuert, 2011.

BÉLy, Lucien (dir.), L’Europe des traités de Westphalie. Esprit de la diplomatie et diplomatie de l'esprit, Paris, Presses Universitaires de France, 2000.

BéLy, Lucien e Isabelle Richefort (dir.), Linvention de la diplomatie, Paris, Presses Universitaires de France, 1998.

Bizzarri, Hugo Ó., "Consejos y consejeros, según Pero López de Ayala», eSpania: revue interdisciplinaire d'études hispaniques médiévales et modernes, 12, 2011a, s. p., <http://e-spania.revues.org/20603>

—, "Pero López de Ayala y sus espejos de príncipes», en Le miroir du prince. Écriture, transmission et réception en Espagne (XIII'-XVI siècle), ed. G. Fournès y E. Canonica, Bordeaux, Presses Universitaires de Bordeaux, 2011b, pp. 165-183.

—, "Sermones y espejos de príncipes castellanos», en La predicación medieval: sermones cristianos, judios e islámicos en el Mediterráneo, Anuario de Estudios Medievales, 42.1, 2012, pp. 163-181.

Boadas Cabarrocas, Sònia, «Diego de Saavedra Fajardo, caballero de la Orden de Santiago", Boletín de la Real Academia Española, 92, 105, 2012a, pp. 5-20.

—, "Grandes diplomáticos en el congreso de Münster: Diego de Saavedra y Josep Fontanella», en Literatura en la Guerra de Treinta Años (Girona, 2426 de noviembre de 2010), ed. S. Boadas Cabarrocas, Vigo, Academia del Hispanismo, 2012b, pp. 151-168.

Bouzy, Christian, "Diego de Saavedra Fajardo ou le diplomate pamphlétaire», en 350 Anniversaire des Traités de Westphalie 1648-1998. Une genèsse de l'Europe, une société à reconstruire, ed. J. P. Kintz y G. Livet, Strasbourg, Presses Universitaires de Strasbourg, 1999, pp. 323-329.

—, «Saavedra Fajardo, diplomático y educador del príncipe», Empresas Políticas, 7, 2006, pp. 139-144.

—, «Diego de Saavedra Fajardo o el diplomático panfletario: una visión española de la paz», Empresas Políticas, 9, 2007, pp. 109-114.

Cardim, Pedro, «Diplomacia y diplomáticos en el tiempo de Saavedra Fajardo», en Saavedra Fajardo, soñar la paz, soñar Europa, ed. I. G. Bango Tovirso, Murcia, Tres Fronteras, 2008, pp. 94-129.

Casado Lobato, Concepción, «Un poeta y diplomático leonés del siglo xvir: Bernardino de Rebolledo", Archivos Leoneses, 57-58, 1975, pp. 21-58.

Chaparro, Sandra, «Mito y razón: religión y política en una historia del mundo del siglo XvI», Foro interno, 3, 2003, pp. 67-86.

Clavería, Carlos, «Gustavo Adolfo y Cristina de Suecia, vistos por los españoles de su tiempo", en Estudios hispano-suecos, Granada, Universidad de Granada, 1954, pp. 101-156. 
—, «Notas generales sobre los godos y su proyección histórica», Cuadernos Hispanoamericanos, 280-282, 1973, pp. 61-67.

Colomer, José Luis, Arte y diplomacia de la Monarquía Hispánica en el siglo XVII, Madrid, Centro de Estudios Europa Hispánica / Casa de Velázquez, 2003.

Corredera Nilsson, Enrique J., "Todos somos godos». Las relaciones hispanosuecas desde la década de 1640 hasta la Paz de Oliva, Madrid, Editorial Complutense, 2009.

—, "Yo he hecho lo que podido y en Praga lo que han querido". El papel mediador de Bernardino de Rebolledo en Copenhague y las limitaciones de la colaboración hispano-imperial en la guerra del Norte (1655-1660)», en La dinastía de los Austria: las relaciones entre la Monarquía Católica y el Imperio, coord. J. Martínez Millán y R. González Cuerva, Madrid, Polifemo, 2011, vol. 1, pp. 507-532.

Covarrubias, Sebastián de, Tesoro de la lengua castellana y española, ed. integral e ilustrada I. Arellano y R. Zafra, Madrid / Frankfurt, Iberoamericana / Vervuert, 2006.

DAdson, Trevor J., "Avisos a un cortesano”: la epístola político-moral del siglo XVII", en La epistola, ed. B. López Bueno, Sevilla, Universidad de Sevilla, 2000, pp. 373-394.

Díaz Plaja, Guillermo, La poesía lírica española, Barcelona, Labor, 1937.

Díez de Revenga, Francisco Javier, «La difusión de la obra de Saavedra Fajardo", Monteagudo, 72, 1981, pp. 51-54.

Dowling, John C., El pensamiento politico-filosófico de Saavedra Fajardo. Posturas del siglo XVII ante la decadencia y conservación de las monarquias, Murcia, Academia Alfonso X el Sabio, 1957.

Duccini, Hélène, Guerre et paix dans la France du Grand Siècle: Abel Servien, diplomate et serviteur de l'Etat (1593-1659), Seyssel, Champ Vallon, 2012.

Ekman, Ernst, "Gothic Patriotism and Olof Rudbeck», The Journal of Modern History, 34.1, 1962, pp. 52-63.

Fernández Albadalejo, Pablo, Materia de España: cultura política e identidad en la España moderna, Madrid, Marcial Pons, 2007.

Fernández-Daza Álvarez, Carmen, El primer conde de la Roca, Mérida, Editora Regional de Extremadura, 1995.

Fraga Iribarne, Manuel, Don Diego de Saavedra y Fajardo y la diplomacia de su época, Madrid, Academia Alfonso X el Sabio, 2008. [Original de 1956.]

Fumaroli, Marc, La diplomacia del ingenio, trad. C. Martínez, Barcelona, Acantilado, 2011. [Original: La diplomatie de l'esprit, Paris, Gallimard, 1998.]

—, "La diplomacia del ingenio», en La República de las Letras, trad. J. R. Monreal, Barcelona, Acantilado, 2013, pp. 200-209. [Original: «La diplomatie de l'esprit», en L'Europe des traités de Westphalie. Esprit de la diplomatie et diplomatie de l'esprit, dir. L. Bély, Paris, Presses Universitaires de France, 2000, pp. 5-11, luego recogido en La République des Lettres,

Galende Díaz, Juan Carlos, «Un diplomático español en la Europa del siglo 
Xvir: Diego de Saavedra Fajardo y su clave criptográfica con Felipe IV», Murgetana, 89, 1994, pp. 55-62. [En red.]

García López, Jorge, "Quevedo y Saavedra: dos contornos del seiscientos», La Perinola, 2, 1998, pp. 237-260. [En red.]

—, «Saavedra Fajardo», en Diccionario filológico de literatura española. Siglo XVII, ed. P. Jauralde, Castalia, Madrid, 2010, pp. 326-338.

—, "Sobre una edición "corregida" de las Empresas politicas», en Literatura medieval y renacentista en España: líneas y pautas, ed. N. Fernández Rodríguez y M. ${ }^{a}$ Fernández Ferreiro, Salamanca, SEMYR, 2012, pp. 575-582.

García López, Jorge (ed.), D. de Saavedra Fajardo, República literaria, Barcelona, Crítica, 2006.

—, D. de Saavedra Fajardo, Poesías, en Rariora et minora, dir. J. L. Villacañas, Murcia, Tres Fronteras, 2008, pp. 69-107.

González Blanco, Antonino, «La Corona gótica de Saavedra Fajardo y el comienzo de la crítica histórica en este tema histórico», en Historiografía de la arqueología y de la historia antigua en España(siglos XVIII $y X X)$, coord. R. Olmos Romera y J. Arce Martínez, Madrid, Instituto de Conservación y Restauración de Bienes Culturales, 1991, pp. 25-29.

González Cañal, Rafael, «El conde de Rebolledo y la reina Cristina de Suecia: una amistad olvidada", Tierras de León, 26, 62, 1986, pp. 93-108.

- "La Vida de Boecio de Francisco de Moncada y el Conde de Rebolledo", Silva: Estudios de humanismo y tradición clásica, 2, 2003, pp. 131-146.

—, "Los epigramas de John Owen y el conde de Rebolledo», en Charisterion, Francisco Martín García oblatum, coord. S. Talavera Cuesta e I. J. García Pinilla, Cuenca, Universidad de Castilla-La Mancha, 2004, pp. 607-618.

—, «El conde de Rebolledo y los albores de la Ilustración», Criticón, 103-104, 2008a, pp. 69-80.

—, "El prosaísmo del conde de Rebolledo", Boletín de la Biblioteca de Menéndez Pelayo, 84, 2008b, pp. 169-186.

—, «Rebolledo, Bernardino de, conde de», en Diccionario filológico de literatura española. Siglo XVII. Vol. 1, dir. P. Jauralde Pou, Madrid, Castalia, 2010, pp. 248-252.

González Cañal, Rafael (ed.), B. de Rebolledo, Ocios, Cuenca, Universidad de Castilla-La Mancha, 1997.

GonZÁlez Fernández, Rafael, «Los godos y la teoría política en el Barroco español: Diego Saavedra Fajardo y la Corona gótica», en Historia y humanismo: homenaje al prof. Pedro Rojas Ferrer, Murcia, Universidad de Murcia, 2000, pp. 137-158.

González Palencia, Ángel, Diego Saavedra Fajardo: su vida y sus obras, Madrid, Aguilar, 1946.

Gramático, Saxo, Historia danesa (Gesta Danorum), ed. y trad, Santiago Ibáńez Lluch, Madrid, Miraguano, XXX.

Hampton, Timothy, Fictions of Embassy: Literature and Diplomacy in Early Modern Europe, Ithaca, Cornell University Press, 2009. 
IbÁÑez Lluch, Santiago, "Saxo Gramático, traductor», Hermeneus: revista de traducción e interpretación, 6, 2004, pp. 1-27.

Johannesson, The Reinassance of the Goths in the Sixteenth-Century Sweden, ed. y trad. James Larson, Berkeley, University of California Press, 1991.

LEFEVre, Joseph, "Les ambassadeurs d'Espagne à Bruxelles sous le règne de l'archiduc Albert (1598-1621)», Revue Belge de Philologie et d'Histoire, 2, 1923, pp. 61-80.

Levin, Michael J., Agents of Empire: Spanish Ambassadors in Sixteenth-Century Italy, Ithaca, Cornell University Press, 2005.

López Cordón, María Victoria, «Diplomacia, propaganda e historia: la publicística española en torno a 1648», en La cultura y la política de España en la prima mitad del siglo XVII, ed. H. Duchhardt y C. Strosetzki, Köln, Böhlau, 1996, pp. 109-127.

Lundell, Richard, «Renaissance Diplomacy and the Limits of Empire: Eustace Chapuys, Habsburg Imperialisms, and Dissimulation as Method», en The Limits of Empire: European Imperial Formations in Early Modern World History. Essays in Honor of Geoffrey Parker, ed. T. Andrade y W. Reyes, Burlington, Ashgate, 2012, pp. 205-222.

Martinengo, Alessandro, "Quevedo, modelo del diplomático tacitista», en Quevedo: fronteras de la filología (con una mirada hacia Gracián), Pamplona, Eunsa, 2006, pp. 41-47. [Antes en: Miscelánea de Estudios Hispánicos. Homenaje de los grandes hispanistas de Suiza a Ramón Sugranyes de Franch, Montserrat, Abadía de Montserrat, 1982, pp. 249-260.

Martín Puya, Ana I., "Periferias de un noble: el conde de Rebolledo», enHeterodoxias y periferias: la poesía hispánica en el Bajo Barroco, ed. I. López Guil, A. J. Sáez, A. Sánchez Jiménez y P. Ruiz Pérez, Versants, 60.3, 2013, pp. 119-129.

Mattingly, Garrett, La diplomacia del Renacimiento, trad. C. de Campo Rey, Madrid, Instituto de Estudios Políticos, 1970. [Original: Renaissance Diplomacy, London, Cape, 1963.]

Menéndez Pelayo, Marcelino, Biblioteca de traductores españoles, Santander, Aldus / CSIC, 1953, vol. 4.

Michon, Cédric y Loris Petris (ed.), Le cardinal Jean Du Bellay. Diplomatie et culture dans l'Europe de la Renaissance, Tours / Rennes, Presses Universitaires François Rabelais / Presses Universitaires de Rennes, 2013.

Mörner, Magnus, «Las relaciones hispano-suecas ante la Paz de Westfalia», Historiar: revista trimestral de historia, 1, 1999, pp. 124-140.

Murillo Ferrol, Francisco, Saavedra Fajardo y la politica del Barroco, Madrid, Centro de Estudios Constitucionales, 1989.

Niemöller, Susanne, «Ideas del Norte en el Siglo de Oro», en Del pensamiento al texto: textualización del saber en el Renacimiento español, ed. F. Gernert, J. Gómez-Montero y F. Serrano, Vigo, Academia del Hispanismo, 2013, pp. 219-240. 
OchoA Brun, Miguel-Ángel, «Los embajadores de Felipe IV» en Felipe IV. El hombre y el reinado, coord. N. Alcalá-Zamora, Madrid, Real Academia de la Historia, Centro de Estudios Europa Hispánica, 2005, pp. 199-234.

Pineda, fray Juan de, Monarquía eclesiástica o Historia universal del mundo, Salamanca, Juan Fernández, 1588.

Prot, Frédéric, «La poésie scientifique de Bernardino de Rebolledo à la lumière du gassendisme», en Poésie et societé en Espagne: 1650-1750, ed. J.-M. Buiguès, Bulletin Hispanique, 115.1, 2013, pp. 13-26.

Rebolledo, Bernardino de (conde), Selvas dánicas, Copenhague, Pedro Morsingio, 1655. [Manejo el ejemplar que se encuentra en la Universidade de Santiago de Compostela, en red(Consulta: 07.04.2014).]

Redondo, Augustin, "Les divers visages du thème (wisi)gothique», en L'Europe héritière de L'espagne wisigothique. Rencontres de la Casa de Velázquez, Madrid, Casa de Velázquez, 1992, pp. 341-352.

Río Alonso, Francisco del, El Conde de Rebolledo y sus obras, León, La Crónica de León, 1927.[Disponible en la Biblioteca Digital de Castilla y León.]

Rivero Rodríguez, Manuel, Diplomacia y relaciones exteriores en la Edad Moderna: 1453-1974, Madrid, Alianza, 2000.

Rosa De GeA, Belén, "Res publica» y poder: Saavedra Fajardo y los dilemas del mundo hispánico, Madrid, Biblioteca Nueva, 2010.

—, "La Corona gótica de Saavedra Fajardo», en Biblioteca Saavedra Fajardo de Pensamiento Político Hispánico, sin fecha.[En red.]

Ruiz PÉrez, Pedro, «Imágenes políticas en la Selva de Rebolledo», Studia Aurea, 8, 2014, pp. 35-90.

SaAvedra Fajardo, Diego, Corona gótica, ed. J. L. Villacañas, Murcia, Tres Fronteras, 2008.

SÁez, Adrián J., «Doctrina, historia y política en cuatro autos de Calderón con la guerra de Cataluña al fondo», en Teatro y religión, ed. J. G. Maestro, Theatralia, 14, 2012a, pp. 119-145.

—, «Embajadas y guerras: algunos paradigmas compositivos en el auto sacramental de Calderón", Anuario Calderoniano, 5, 2012b, pp. 215-231.

Sánchez Jiménez, Antonio, y Adrián J. SÁez, Saavedra Fajardo y la Confederación Helvética: contexto y tres textos de una relación, Kassel, Reichenberger, 2014.

Sanmartín, José J., "Saavedra y el goticismo», Res Publica, 17, 2007, pp. $201-$ 223. [En red.]

Siracusa, Joseph M., Diplomacy. A Very Short Introduction, Oxford, Oxford University, 2010.

SöHRMAN, Ingmar, «La tradición goda: su presencia en la época del Barroco», en España y Suecia en la época del Barroco (1660), ed. Enrique Martínez Ruiz y M. de P. Pi Corrales, Madrid, Consejería de Educación y Cultura, 1998, pp. 945-956.

—, «El goticismo: el último florecimiento de una vieja historia», en Relaciones entre España y Suecia desde mediados del siglo XVII hasta comienzos del siglo XIX, 
ed. K. Benson, M. Mörner e I. Sörhman, Göteborg, Göteborgs Universiteit, 2002, pp.

—, "Ecos de la patria goda: el origen de dos naciones», Revista de ideas y formas políticas de la Antigüedad Clásica, 16, 2005a, 169-196

—, "La estirpe visigoda: concepto fundador de dos naciones», en Acta antiqua complutensia $V$, 2005b, pp. 181-200.

—, "Godos, gauditas y gotios: etónimos nebulosos y reveladores», en Actas del VI Congreso Internacional de Historia de la Lengua Española, coord. J. L. Girón Alconchel y J. J. de Bustos Tovar, Madrid, Arco Libros, 2006, vol. 2, pp. 1731-1740.

Villacañas, José Luis (ed.), Diego Saavedra Fajardo, Corona gótica, Murcia, Tres Fronteras, 2008.

Weller, Thomas, «Poder político y poder simbólico: el ceremonial diplomático y los límites del poder durante el Siglo de Oro español», en Autoridad y poder en el Siglo de Oro, ed. I. Arellano, C. Strosetzki y E. Williamson, Madrid / Frankfurt, Iberoamericana / Vervuert, 2009, pp. 213-239. 